\title{
AS DISCIPLINAS RÍTMICAS E DANÇANTES NOS CURSOS DE LICENCIATURA EM EDUCAÇÃO FÍSICA DO ESTADO DO PARANÁ ${ }^{85}$
}

\author{
Deisy de Oliveira Silva \\ Universidade Estadual de Maringá, Maringá, Paraná, Brasil \\ Juliana Pizani \\ Universidade Estadual de Maringá, Maringá, Paraná, Brasil \\ Evandra Hein Mendes \\ Universidade Estadual do Oeste do Paraná, Marechal Candido Rondon, Paraná, Brasil \\ Ieda Parra Barbosa-Rinaldi \\ Universidade Estadual de Maringá, Maringá, Paraná, Brasil
}

\begin{abstract}
Resumo
O estudo de caráter descritivo objetivou analisar como estão organizadas as disciplinas rítmicas e dançantes presentes em cursos de licenciatura em educação física do Paraná, com vistas à identificação de aproximações e/ou distanciamentos com as diretrizes curriculares da educação básica do estado. Os dados foram compostos por documentos de 12 instituições que oferecem o curso de licenciatura em educação física. Para o tratamento dos dados utilizamos análise de conteúdo e estatística descritiva. Os resultados indicam que os cursos oferecem disciplinas rítmicas e dançantes que se diferenciam entre os cursos quanto aos conteúdos e referenciais, e que há aproximações entre os conteúdos programáticos, ementas e objetivos com o preconizado nas diretrizes curriculares.
\end{abstract}

Palavras-chave: Dança. Educação física. Educação superior. Currículo.

\section{Introdução}

O desenvolvimento da educação brasileira ao longo de sua história esteve atrelado às tratativas descritas nos documentos oficiais que regulamentam e balizam os currículos escolares e dos cursos de ensino superior. Dentre eles, podemos citar os Parâmetros Curriculares Nacionais (PCNs), as Diretrizes Curriculares Nacionais (DCNs), o Plano Nacional de Educação (PNE) e, especificamente, no que se refere à educação física no estado do Paraná, temos as Diretrizes Curriculares Estaduais da Educação Básica do Paraná (DCEs),

${ }^{85} \mathrm{O}$ artigo apresenta dados referentes ao Projeto de Pesquisa intitulado "Panorama da formação inicial em educação física no estado do Paraná", contemplado com fomento do Edital Universal MCT/Conselho Nacional de Pesquisa (CNPq). 
as quais são utilizadas nesse estudo como referência para compreender se os conhecimentos sugeridos são contemplados na formação de professores.

Nessa perspectiva, indaga-se: estando as manifestações rítmicas e dançantes presentes como disciplinas curriculares nos cursos de licenciatura em educação física e sendo a dança integrante da cultura corporal de movimento a ser tematizada pela educação física escolar, como vem sendo tratada no decorrer da formação profissional? São estabelecidas relações no decorrer do processo de ensino e aprendizagem com a futura prática pedagógica e com as Diretrizes Curriculares para a Educação Básica do Estado do Paraná?

Nessa direção, a Resolução CFE n.03/1987 desempenha importante papel, visto que a partir de sua promulgação, as Instituições de Ensino Superior (IES) conquistaram autonomia para organizarem seus próprios currículos, e com isso as manifestações rítmicas e dançantes passam a ser inseridas nos cursos de graduação de forma mais expressiva.

Já no contexto escolar, a área ganhou status legal de componente curricular com a Lei de Diretrizes e Bases n.9394/1996. Aqui a dança e as atividades rítmico-expressivas se constituem em conteúdos considerados relevantes e que proporcionam o desenvolvimento da capacidade criativa, a percepção das possibilidades de movimento do corpo e as relações com os outros, colaborando para o alcance das potencialidades humanas.

Mesmo dada a importância da presença da dança como conhecimento a ser tratado na escola, ainda situamos como problemática a sua falta de legitimidade, sendo esta sustentada por aspectos como: predominância de seu desenvolvimento na educação física escolar sob a forma de apresentações em datas festivas; o trato reduzido ao ensino técnico estilístico e a exercícios convencionais; pré-conceitos em relação à prática da dança por meninos; recursos físicos e materiais inadequados; e despreparo profissional que, em geral reflete à formação inicial (SBÓRQUIA; PEREZ GALLARDO, 2002; FIAMONCINI 2003; BRASILEIRO, 2008; SOUSA; HUNGER; CARAMASCHI, 2010, 2014).

De fato, a superficialidade no trato deste conteúdo ainda na formação inicial desconexo de sua aplicabilidade e importância para a futura atuação profissional se constitui em um dos pontos cruciais para a falta de legitimidade e/ou quase exclusão da dança na escola, já que o futuro professor na maior parte dos casos construirá sua prática pedagógica alicerçada nos conhecimentos incorporados durante o processo formativo. (AMORIN et al, 2012). Guzzo et al. (2015) frisam que o conhecimento sobre a sua história e sua potência política-transformadora para/com o corpo que circula nos conteúdos e cursos de formação bem como nas pesquisas e nas práticas profissionais da Educação Física ainda são diminutos e, muitas vezes, os conteúdos práticos se sobressaem, focados numa dança meramente reprodutiva que se resume no ensino de "passos de dança".

Ainda vale destacar que a dança, especialmente no contexto escolar, se trata de uma área de conhecimento que compõe o rol de conteúdo da Educação Física e das Artes, sendo, por vezes, difícil identificar a linha tênue que separa uma da outra. De acordo com os PCNs, as aproximações são existentes, quer seja em seus conteúdos, objetivos ou intenção artística, cultural e movimento corporal. No entanto, mesmo tendo ciência que se trata de um conteúdo compartilhado e com forte enraizamento nas Artes, esta pesquisa é embasada em discussões que tomam como foco à educação física, uma vez que buscamos evidenciar o modo como a dança e as atividades rítmicas expressivas estão sendo abordadas na formação inicial da área.

Dessa forma, podemos afirmar que são inúmeras as possibilidades de desenvolvimento de um trabalho com a dança no contexto escolar, seja por meio das artes ou da educação física que é foco dessa pesquisa. De acordo com Guimarães (2003), Fiamoncini (2003), Guzzo et al. (2015), entre outros, a dança é capaz de produzir um movimento crítico sobre a realidade e de 
produzir reflexão sobre as condições e necessidades coletivas. Isso porque é entendida como uma forma de comunicação e arte e proporciona experiências ligadas à estética/sensibilidade, criatividade, expressão etc.

Com o intuito de compreender melhor esse fenômeno, elegemos o seguinte objetivo: analisar, por meio de documentos, como estão organizadas as disciplinas rítmicas e dançantes presentes em cursos de licenciatura em educação física do Paraná, com vistas à identificação de aproximações e/ou distanciamentos com as diretrizes curriculares que norteiam a educação básica neste estado.

\section{Metodologia}

A presente pesquisa caracteriza-se como descritiva que, segundo Cervo e Bervian (1996, p. 49), "é aquela que observa, registra, analisa e correlaciona fatos ou fenômenos (variáveis) sem manipulá-los". De acordo com Gil (2002), esse tipo de pesquisa tem como objetivo primordial a descrição das características de determinado fenômeno ou população ou, então, o estabelecimento de relações entre variáveis.

Elegemos também para esse estudo a pesquisa do tipo documental que, a partir das incursões feitas por Neves (1996, p.03), “é constituída pelo exame de materiais que ainda não receberam um tratamento analítico ou que podem ser reexaminados com vistas a uma interpretação nova ou complementar"..

Nesse sentido, analisamos os seguintes documentos dos cursos de licenciatura em educação física das IES do estado do Paraná: matriz curricular, ementas, conteúdos programáticos, objetivos e referenciais teóricos relacionados com as manifestações rítmicas e dançantes.

Com o objetivo de definir os participantes do estudo, num primeiro momento, fizemos um levantamento das IES que possuem o curso de licenciatura em educação física conforme previsto nas Resoluções CNE/CP n.01 e 02/2002, totalizando, de acordo com as IES e cursos cadastrados apresentados pelo MEC (http://emec.mec.gov.br/), 37 instituições. Inicialmente, enviamos carta convite para todas as IES, em que todas aceitaram participar da pesquisa. Contudo, devido à liberdade de desistência expressa no termo de consentimento livre e esclarecido assinado pelos participantes, a amostra reduziu-se para 23 instituições. Ainda vale destacar que, pelo fato da não disponibilização dos documentos necessários para a pesquisa, 11 IES foram excluídas da amostra. Dessa forma, a amostra final foi composta por 12 IES.

Para melhor compreensão das análises realizadas, salientamos que, apenas 4 IES disponibilizaram todos os documentos solicitados (matriz curricular, ementas, conteúdos programáticos, objetivos e referencial teórico) e 8 disponibilizaram parte dos documentos, o que ocasionou a não participação em algumas análises.

Para o tratamento dos documentos (matriz curricular, ementas, conteúdos programáticos, objetivos e referenciais teóricos) fizemos uso da técnica de análise de conteúdo proposta por Bardin (1977, p.38), a fim organizar os dados para melhor interpretar os resultados, a qual é entendida "como um conjunto de técnicas de análise das comunicações, que utiliza procedimentos sistemáticos e objetivos de descrição do conteúdo das mensagens". Aplicamos assim, a análise categorial, dentre as várias possibilidades de categorização, a qual "consiste em descobrir núcleos de sentido que compõem a comunicação e cuja presença, ou freqüência de aparição podem significar alguma coisa para o objetivo analítico escolhido" (BARDIN, 1977, p. 105). 
Ressaltamos que essa pesquisa encontra-se vinculada a um Projeto de Pesquisa apresentado ao Edital Universal MCT/Conselho Nacional de Pesquisa (CNPq), n. 14/2009, tendo como título "Panorama da formação inicial em educação física no Estado do Paraná", e, que o mesmo foi aprovado pelo Comitê Permanente de Ética em Pesquisa envolvendo Seres Humanos (CONEP) sob Parecer n. 247/2010. Todos os pesquisados foram informados sobre a divulgação e publicação dos dados coletados no estudo, bem como foram obtidas as respectivas assinaturas dos termos de consentimento livre e esclarecido dos responsáveis dos participantes.

\section{Resultados e discussão}

A partir da coleta dos dados junto as IES do Paraná tornou-se possível identificar diversos aspectos relativos à organização e implementação das disciplinas rítmicas e de dança, entre eles, a carga horária, o número de disciplinas, as ementas, os conteúdos abordados, os objetivos e os referenciais teóricos que serão discutidos a seguir.

Inicialmente apresentamos no quadro 1 a carga horária destinada e número de disciplinas por IES das disciplinas rítmicas e de dança.

\begin{tabular}{|c|c|c|}
\hline IES & $\begin{array}{c}\text { Número de } \\
\text { disciplinas }\end{array}$ & $\begin{array}{c}\text { Somatória da } \\
\text { carga horária }\end{array}$ \\
\hline 1 & 2 & 204 \\
\hline 2 & 1 & 120 \\
\hline 3 & 2 & 120 \\
\hline 4 & 4 & 204 \\
\hline 5 & 3 & 204 \\
\hline 6 & 1 & 68 \\
\hline 7 & 1 & 68 \\
\hline 8 & 1 & Não disponibilizou \\
\hline 9 & 1 & 80 \\
\hline 10 & 1 & 120 \\
\hline 11 & 1 & 54 \\
\hline 12 & 1 & Não disponibilizou \\
\hline
\end{tabular}

Quadro 1: Carga horária das disciplinas rítmicas e dançantes das IES do estado do Paraná.

Os resultados obtidos apontam que os cursos de licenciatura em educação física das 12 IES pesquisadas oferecem, minimamente, uma disciplina relacionada às manifestações rítmicas e dançantes. Alguns cursos apresentaram disciplinas optativas relacionadas à temática, porém estas não foram analisadas pelo fato de não haver obrigatoriedade do aluno cursá-la e nem de ser oferecida em todos os anos do curso.

A presença de disciplinas relacionadas às manifestações rítmicas e dançantes na formação inicial, em menor ou maior quantidade, parece ainda não legitimar a presença deste conteúdo na escola, como apontam os estudos de Peres, Ribeiro e Martins Júnior (2001), Sborquia e Pérez Gallardo (2002) Brasileiro (2008) e Sousa, Hunger e Caramaschi (2010).

Mais uma vez, um paradoxo envolvendo a dança, a Arte e a Educação Física emergem nas discussões pois, ao atentar-se para o fato de que a dança é um conteúdo que se faz 
presente nos cursos de formação inicial de professores destas duas áreas do conhecimento, Brasileiro (2008) salienta que ela deveria existir em mais de uma disciplina também, o que não se confirma na realidade educacional.

Em geral as manifestações da dança na escola ocorrem em datas comemorativas, em eventos sociais e/ou em apresentações de final de ano (LARA, 2007; BRASILEIRO, 2008; CORREAA; SANTOS, 2014), sobretudo as danças folclóricas, as quais via de regra são transmitidas mecanicamente pelos professores e reproduzida pelos alunos, um processo irrefletido sem nenhuma ponderação sobre "sua constituição histórica, de sua função social para as comunidades que a realizam, de sua importância como construção cultural de uma dada coletividade" (LARA, 2007, p.165).

Num estudo realizado sobre o ensino da dança na ótica de professores de Educação Física e de Arte do ensino fundamental numa cidade do Estado de São Paulo, Sousa, Hunger e Caramashi (2014) apontam que 62\% dos professores de Educação Física e 16\% de Artes indicam que trabalham com a dança somente em festas do calendário escolar ou nas datas comemorativas. Esta diferença relevante entre as respostas obtidas pelos autores supracitados são preocupantes e ratificam o quão desafiador é para os docentes tornar a dança um conhecimento presente no processo de formação e intervenção pedagógica na escola, fortalecendo a necessidade de que os cursos de licenciatura, seja em Educação Física ou em Artes, promovam uma formação que possibilite o efetivo trabalho com a dança no âmbito escolar.

Para além de investigar a presença das disciplinas rítmicas e dançantes nos currículos dos cursos de educação física do Paraná, por meio da verificação do número de disciplinas e as cargas horárias que cada instituição destinava a elas, foram analisadas as características teórico-metodológicas dessas disciplinas a partir das ementas, objetivos, conteúdos e referenciais teóricos.

O quadro 2 apresenta a análise da frequência por categorias das ementas, dos objetivos e dos conteúdos constantes no total das disciplinas rítmicas e dançantes das IES pesquisadas.

\begin{tabular}{|l|c|c|c|}
\hline Categorias das disciplinas rítmicas e dançantes & $\begin{array}{c}\text { Ementas } \\
\%\end{array}$ & $\begin{array}{c}\text { Objetivo } \\
\%\end{array}$ & $\begin{array}{c}\text { Conteúdo } \\
\%\end{array}$ \\
\hline $\begin{array}{l}\text { Aspectos históricos, sociais e culturais dos ritmos } \\
\text { e dança }\end{array}$ & 82 & 40 & 75 \\
\hline $\begin{array}{l}\text { Aspectos metodológicos do ensino da rítmica e } \\
\text { dança }\end{array}$ & 64 & 100 & 100 \\
\hline Objetivos/benefícios e funções dos ritmos e dança & 64 & 20 & 50 \\
\hline $\begin{array}{l}\text { Elementos constituintes do ritmo/métrica } \\
\text { musical/ritmoplastia }\end{array}$ & 55 & 40 & 88 \\
\hline $\begin{array}{l}\text { Importância/influência dos ritmos e dança para a } \\
\text { vida }\end{array}$ & 45 & 80 & 88 \\
\hline $\begin{array}{l}\text { Sensibilização, expressão, consciência, linguagem } \\
\text { corporal }\end{array}$ & 45 & 40 & 63 \\
\hline $\begin{array}{l}\text { Modalidades/tipos manifestações rítmicas e } \\
\text { dançantes: brinquedos cantados, cantigas de roda; } \\
\text { e de dança: de salão, folclórica, criativa, de rua, } \\
\text { clássica, moderna, jazz. }\end{array}$ & 45 & 20 & 88 \\
\hline Conceituação de ritmo e dança & 36 & 40 & 63 \\
\hline Aspectos técnico/pedagógicos do ensino dos & 36 & 40 & 75 \\
\hline
\end{tabular}




\begin{tabular}{|l|c|c|c|}
\hline ritmos e dança & & & \\
\hline $\begin{array}{l}\text { Composições coreográficas, improvisação, } \\
\text { processo criativo }\end{array}$ & 36 & 80 & 88 \\
\hline $\begin{array}{l}\text { Aspectos crítico/reflexivos do ensino da rítmica e } \\
\text { dança }\end{array}$ & 0 & 20 & 25 \\
\hline
\end{tabular}

Quadro 2: Ementas, objetivos e conteúdos das disciplinas rítmicas e dançantes dos cursos de licenciatura em educação física das IES do estado do Paraná.

Ao comparar as ementas, os objetivos e os conteúdos dos programas das disciplinas rítmicas e dançantes das IES pesquisadas, foi possível identificar similaridades entre eles, já que as diferentes categorias apresentam-se contempladas nos três itens analisados, com exceção da categoria "aspectos crítico/reflexivos do ensino da rítmica e dança".

Analisando especificamente as ementas observa-se predominância dos aspectos históricos, sociais, culturais, metodológicos, bem como dos objetivos/benefícios e funções dos ritmos e dança. Da mesma forma, em estudo realizado por Amorin et al. (2012) constatou-se que a maioria das disciplinas de dança contempla nas ementas sua história, seus estilos, tipos de movimentação, deslocamentos e técnicas como tema em comum.

No que se refere aos objetivos das disciplinas rítmicas e dançantes verificou-se ênfase nos aspectos metodológicos do ensino da dança, na composição de coreografias, no desenvolvimento da criatividade e improvisação, na percepção da influência do ritmo e da dança para a vida cotidiana dos indivíduos.

Da mesma forma, no que diz respeito aos conteúdos presentes nos programas das disciplinas rítmicas e dançantes destacam-se os aspectos metodológicos do ensino, a importância/influência dos ritmos e dança para a vida, os elementos constituintes do ritmo, as composições coreográficas, o processo criativo, as modalidades de dança e manifestações rítmicas, os aspectos históricos, sociais, culturais e técnico/pedagógicos de ensino e aprendizagem dos diferentes ritmos e dança.

De modo geral, nota-se que os conteúdos abordados pelas disciplinas permeiam três dimensões dos conteúdos da dança frisados por Marques (1997), sendo eles: 1) aspectos e estruturas do aprendizado do movimento (coreologia, consciência corporal e condicionamento físico); 2) contextualização da dança (história, estética, apreciação e crítica, sociologia, antropologia, música, anatomia, fisiologia e cinesiologia); e 3) possibilidades de vivenciar a dança em si (repertórios, improvisação e composição coreográfica). Entretanto, a categoria referente aos aspectos crítico/reflexivos do ensino da rítmica e dança se constituiu menos evidente (25\%), e em relação aos aspectos metodológicos do ensino e aprendizagem dos ritmos e dança foram mais evidenciadas $(100 \%)$ quando comparadas às outras categorias de análise.

Esse fato demonstra a preocupação em preparar o futuro profissional para ensinar ou ministrar atividades relacionadas ao tema em uma perspectiva técnico-instrumental e a despreocupação com o ensino voltado à reflexão crítica acerca do conteúdo em questão. Nesse sentido, a dança continuará sendo trabalhada eventualmente como sinônimo de festividade e/ou com a finalidade de apresentação em dias comemorativos, sobretudo reproduzindo as danças veiculadas pela mídia, descontextualizadas e sem reflexões sobre as implicações para a sociedade (SBORQUIA; PÉREZ GALLARDO, 2002), quando não performáticas e excludentes.

Com efeito, a dança desempenha papel importante para a formação humana, visto que possibilita a experienciação por parte dos alunos, bem como contribui para a concepção de 
novos olhares sobre diferentes assuntos, uma vez que envolve a sensibilidade e conscientização de valores, atitudes e ações sociais (GARIBA; FRANZONI; 2007).

Contudo, Strazzacappa e Morandi (2006) afirmam que no âmbito escolar o verbo "dançar" raramente aparece em seu sentido literal da palavra, apropriando-se como uma expressão de linguagem coloquial com o significado de "se dar mal" em algo. Os alunos "dançam" em matemática, em geografia, em química, só parecem não dançar em Arte e Educação Física, não obstante, a temática/problemática do trabalho com a dança na escola parece ir para além destas duas áreas do conhecimento.

Isto porque, como frisa Strazzacappa (2014) o ensino da dança neste ambiente pode ser pensado sob diferentes perspectivas, dentre elas a do professor de arte, do professor de educação física, do professor de dança/licenciado em dança ou ainda do professor de sala, popularmente conhecido como polivalente. Destarte, a autora aponta que o tema atinge também a Pedagogia, uma vez que esses polivalentes, professores da educação básica dos anos iniciais do ensino fundamental que lecionam todas as disciplinas, também são responsáveis pelo trabalho com a dança.

Apesar de algumas IES já terem incluído disciplinas que abordam as linguagens artísticas e/ou atividades com este foco na matriz curricular dos cursos de Pedagogia, salientase que há um desequilíbrio entre a prática e a teoria e que a formação artística do educador é ainda mínima ou nula, ressaltando a necessidade de que as linguagens artísticas se façam igualmente presentes nos cursos de formação de professores e pedagogos que atuarão nos anos iniciais da educação básica (MARTINS et al., 2012; STRAZZACAPPA, 2014). Considerando que o presente estudo tem como foco a área da Educação Física, corroboramos com Gomes Junior et al. (2002), ao indicar a necessidade da educação física estreitar mais seus laços de diálogo com outros campos de conhecimento, para então poder se apresentar como uma forma criativa de interferir na sociedade, utilizando a dança como elemento transformador e libertador do homem (GOMES JUNIOR et al., 2002).

Nesse sentido, é ainda preocupante, na opinião de Brasileiro (2002-2003) reconhecer a quais elementos os profissionais de educação física estão se aproximando no trato da dança no espaço escolar, apesar do contexto da formação inicial em educação física apresentar um avanço significativo nos currículos em relação ao conhecimento dança.

Tal avanço pode ser detectado a partir da inclusão da dança como conteúdo em disciplinas nos cursos de graduação em educação física, assim como nos documentos oficiais destinados aos níveis de ensino fundamental e médio como os PCNs e as DCEs.

Considerando que esses documentos regem e orientam os rumos da educação física no país, percebeu-se a necessidade de investigar as relações de aproximações e distanciamentos entre os objetivos e conteúdos relacionados à dança e ao ritmo nas DCEs e nos programas das disciplinas rítmicas e dançantes da IES participantes da investigação, como pode ser visualizado no quadro 3. 


\begin{tabular}{|c|c|}
\hline \multicolumn{2}{|c|}{ Objetivos e Conteúdos } \\
\hline IES & DCEs \\
\hline $\begin{array}{l}\text { Elementos constituintes do ritmo/métrica } \\
\text { musical/ritmoplastia. }\end{array}$ & $\begin{array}{l}\text { Elementos de movimento (tempo, espaço, } \\
\text { peso e fluência); qualidades de } \\
\text { movimento, Construção de instrumentos } \\
\text { musicais. }\end{array}$ \\
\hline $\begin{array}{l}\text { Processo criativo, de composições } \\
\text { coreográficas e improvisação. }\end{array}$ & $\begin{array}{l}\text { Interpretação, criação e adaptação } \\
\text { coreográfica, improvisação. Organização } \\
\text { de festivais de dança. }\end{array}$ \\
\hline $\begin{array}{l}\text { Modalidades/tipos manifestações rítmicas: } \\
\text { brinquedos cantados, cantigas de roda e de } \\
\text { dança, dança de salão, dança folclórica, } \\
\text { dança criativa, dança de rua, dança } \\
\text { clássica, dança moderna e jazz. }\end{array}$ & $\begin{array}{l}\text { Modalidades/tipos manifestações rítmicas: } \\
\text { danças folclóricas, danças de salão, danças } \\
\text { de rua, danças criativas, atividades de } \\
\text { expressão corporal e danças circulares. }\end{array}$ \\
\hline $\begin{array}{l}\text { Aspectos históricos, sociais e culturais dos } \\
\text { ritmos e dança. }\end{array}$ & $\begin{array}{l}\text { Origem e histórico das danças. Recorte } \\
\text { histórico delimitando tempos e espaços. } \\
\text { Dança relacionada a expressão corporal e } \\
\text { a diversidade de culturas }\end{array}$ \\
\hline $\begin{array}{l}\text { Aspectos técnico/pedagógicos dos ritmos e } \\
\text { dança. }\end{array}$ & $\begin{array}{l}\text { Elementos e técnicas de dança. } \\
\text { Diversidade da dança e seus diferenciados } \\
\text { ritmos. }\end{array}$ \\
\hline $\begin{array}{l}\text { Sensibilização, expressão, consciência, } \\
\text { linguagem corporais }\end{array}$ & $\begin{array}{l}\text { Experimentação de movimentos corporais } \\
\text { rítmico/expressivos. Dança como } \\
\text { possibilidade de dramatização e expressão } \\
\text { corporal. }\end{array}$ \\
\hline $\begin{array}{l}\text { Aspectos crítico/reflexivos da rítmica e } \\
\text { dança. }\end{array}$ & $\begin{array}{l}\text { Provocar a reflexão acerca da apropriação } \\
\text { da Dança pela Indústria Cultural. }\end{array}$ \\
\hline Conceituação de ritmo e dança & \\
\hline $\begin{array}{l}\text { Objetivos/Benefícios e funções dos ritmos } \\
\text { e dança }\end{array}$ & \\
\hline $\begin{array}{l}\begin{array}{l}\text { Aspectos metodológicos dos ritmos e } \\
\text { dança }\end{array} \\
\end{array}$ & \\
\hline $\begin{array}{l}\text { Influência dos ritmos e dança na para a } \\
\text { vida }\end{array}$ & \\
\hline
\end{tabular}

Quadro 3: Comparação dos objetivos e conteúdos das disciplinas rítmicas e dançantes das IES com as DCEs do Paraná.

Observa-se no quadro 3 que a maioria das disciplinas rítmicas e dançantes apresenta aproximações com o estabelecido nas DCEs no que se refere aos objetivos e conteúdos propostos. No entanto, verificou-se maior diversidade de conteúdos e objetivos relacionados aos ritmos e danças nos programas das disciplinas destinadas a esse tema quando comparados aos apontados pelas DCEs. Esse fato pode estar relacionado à preocupação em subsidiar a futura atuação do professor de educação física a partir de discussões, de cunho técnico ou metodológico, próprios dessa fase de preparação profissional.

Assim sendo, reconhecemos a partir da análise dos objetivos e conteúdos programáticos das referidas IES, que os elementos articuladores, propostos pelas DCEs, como a mídia, a saúde, o corpo, a desportivização, a técnica e a tática, a ludicidade, a diversidade, o 
lazer e o mundo do trabalho, caracterizados como meios e fins do processo ensinoaprendizagem nas escolas se fazem também presentes no trabalho docente de professores do ensino superior. Contudo, entendemos que a presença desses elementos nos documentos analisados não garante que os mesmos sejam contemplados na prática docente, tanto no ensino superior como na escola.

Apesar disso, sobre os desafios da inclusão da dança nos documentos oficiais como os PCNs e as DCEs, Antunes (2013) indica que a importância do ensino da dança tanto como área de conhecimento específico quanto linguagem artística apresenta-se reconhecida, entretanto, exige que as universidades a partir de sua atuação assegurem as condições mínimas de formação profissional para o ensino da dança pautada nas orientações legais sobre $\mathrm{a}$ área.

Buogo e Lara (2011) ressaltam que por se tratar de um documento oficial da Secretaria de Estado da Educação do Paraná, as DCEs tendem a ser apropriadas pelos professores em suas aulas, e mesmo que estes tenham dificuldades no trato com este conhecimento, precisam preparar-se adequadamente para trabalhá-lo com os alunos, levando em consideração as especificidades de cada processo de formação e aquilo que lhe dá sustentação.

As DCEs adotam o currículo disciplinar como forma de organização do conhecimento científico historicamente produzido apresentando-se como um instrumento que marca uma concepção pedagógica com suas escolhas teóricas, metodológicas e avaliativas propondo uma reinterpretação em relação ao Currículo Básico (adotado no Paraná a partir de 1990) e uma mudança em relação aos PCNs (VANDRESEN, 2011).

Outro elemento relevante e que foi analisado nos cursos de formação de professores foi o referencial teórico listado nos programas das disciplinas rítmicas e dançantes, já que possibilitam compreender a linha teórica utilizada pelos cursos, além de identificar sua aproximação com os documentos oficiais da área como as DCEs no estado do Paraná.

Dessa forma, o quadro 4, apresenta a categorização do banco de dados sobre referencial teórico básico e complementar dos programas das disciplinas de seis IES que disponibilizaram essas informações.

\begin{tabular}{|l|l|l|}
\hline BIBLIOGRAFIAS/ÁREAS & Obras (n) & \% \\
\hline Dança & 32 & 41,6 \\
\hline Ritmos/Linguagem musical/música & 16 & 20,8 \\
\hline Folclore e Cultura & 8 & 10,4 \\
\hline Teorias pedagógicas/Epistemologia & 7 & 9,1 \\
\hline Ginástica & 4 & 5,2 \\
\hline Metodologia de ensino/Didática & 3 & 3,9 \\
\hline Linguagem corporal/expressão & 3 & 3,9 \\
\hline PCNs e DCEs & 2 & 2,6 \\
\hline Capoeira & 2 & 2,6 \\
\hline Total & 77 & 100 \\
\hline
\end{tabular}

Quadro 4: Categorização do referencial teórico básico e complementar das disciplinas rítmicas e dançantes.

Observa-se que os resultados que a maioria das obras utilizadas se caracterizava como específicas do tema dança (41,6\%); ritmos/linguagem musical/música (20,8\%); e folclore e cultura $(10,4 \%)$. Faz-se importante salientar ainda que as DCEs (2008) se fizeram presentes 
no referencial teórico de poucas disciplinas, o que pode ser um indicativo de que esteja sendo abordada de maneira insuficiente durante a formação inicial. Tal constatação pode constituirse um problema para a área, pois as IES estão formando professores que poderão atuar na rede pública de ensino, sendo, portanto, necessário conhecimento sobre tal documento norteador do trabalho docente nas escolas.

Outro ponto de análise centra-se na frequência com que o referencial apresentado no quadro 4 se fez presente nos programas destas instituições. Constatamos que a obra Domínio do movimento (LABAN, 1978) foi a que apresentou maior frequência, sendo elencada como referência por quatro das seis IES. As obras de Faro (1986), Ossona (1988), Laban (1990), Barreto (2008) e Marques (2003) aparecem em seguida, fazendo-se presentes em três IES. Das demais obras, 13 apareceram no referencial de duas instituições e outras 58 em apenas uma delas. Podemos notar que as referências que aparecem com maior frequência são específicas da área da dança, contudo, mesmo sendo obras clássicas, não são utilizadas por todas as instituições pesquisadas.

Identifica-se ainda a utilização de livros publicados em média há 10 anos e baixa incidência de artigos listados nos referenciais teóricos. Nesse sentido, torna-se necessário acompanhar as publicações mais recentes da área que em geral são divulgadas em periódicos científicos e livros, buscando manter a atualização do curso frente à produção de conhecimento sobre a temática abordada.

Levando em consideração que o objetivo da pesquisa buscou identificar aproximações e/ou distanciamentos das disciplinas rítmicas e dançantes com as diretrizes curriculares que norteiam a educação básica no estado do Paraná, vale destacar a importância de selecionar as referências tomando como base as especificidades do contexto em qual o curso está inserido, em nosso caso as Diretrizes Curriculares para a Educação Básica do referido estado.

\section{Considerações finais}

De maneira geral foi possível perceber semelhanças entre os conteúdos programáticos, ementas e objetivos das disciplinas que envolviam o tema ritmos e dança. Ao contrário, constatamos que, apesar das IES pertencerem a um mesmo estado, a matriz curricular dos cursos em questão, apontam diversidades quanto aos seus conteúdos e bases teóricas.

Essa divergência pode ser resultado da autonomia universitária, legitimada a partir de seu estatuto histórico com a promulgação da Resolução CFE n.03/1987, que desobrigou a existência de um currículo mínimo para os cursos, que pode ter causado falta de documentos norteadores para IES. Nesse sentido, identifica-se a relevância de propor orientações concretas com o intuito de auxiliar na construção de um consenso mínimo sobre os aspectos a serem abordados na formação inicial, já que a dança se constitui um conteúdo recente em muitos currículos de graduação em educação física e ainda encontra dificuldades em se efetivar no contexto escolar.

A categoria que se refere aos aspectos metodológicos do ensino e aprendizagem dos ritmos e dança predominou nos objetivos e conteúdos dos planos das disciplinas quando comparadas as outras categorias de análise. Em contrapartida, os aspectos crítico/reflexivos constituiu-se a categoria menos evidente, indicando uma formação profissional voltada mais para a dimensão técnica-instrumental do que para a crítica-reflexiva de ensino.

Comparando os objetivos e conteúdos do ensino dos ritmos e dança constantes nas Diretrizes Curriculares para a Educação Básica do Estado do Paraná - Educação Física e os programas de disciplinas das IES, percebemos aproximações entre ambos, evidenciando que 
os conhecimentos básicos para o trabalho com a dança nas aulas de educação física escolar vêm sendo abordados na formação inicial em consonância com o preconizado nos documentos oficiais da área, apesar desse constituir o referencial teórico de apenas algumas disciplinas.

Nessa direção é preciso entender os motivos da ausência das manifestações rítmicas e dançantes no contexto escolar de forma legítima a partir de uma reflexão sobre como se efetiva na prática pedagógica o previsto nos currículos da formação inicial. Alguns fatores que limitam a concretização desses saberes na escola já foram identificados como problemas estruturais físicos escolares e a incipiente experiência com a dança ao decorrer da vida dos futuros professores, o que leva a sensação de insegurança no trato desses conhecimentos nas aulas.

Em suma os resultados apontam para novos estudos acerca do processo de construção das práticas pedagógicas pelos professores no decorrer da vida relacionadas ao tema ritmos e dança.

Torna-se necessário ressaltar ao final dessa investigação que nem todas as IES pesquisadas disponibilizaram a documentação em sua totalidade, especialmente no que se refere aos objetivos, conteúdos programáticos e referenciais básicos das disciplinas rítmicas e dançantes, podendo ser considerada uma limitação do estudo, porém não o invalida.

\section{Referências}

AMORIN, D. C.; GUIMARÃES, A.C.A.; SOARES, A.; MACHADO, Z. Rítmica e dança nos currículos dos cursos de educação física. Revista Pensar a prática. Goiânia, v. 15, n. 3, p. 551-820, jul./set., 2012.

ANTUNES, R. C. F. S. Corpoarte: releitura do corpo na educação a partir da plataforma educação física, arte, dança. In: LARA, L.M. Dança: dilemas e desafios na contemporaneidade. Maringá: Eduem, 2013.

BARDIN, L. Análise de conteúdo. Lisboa: Edições 70, 1977.

BARRETO, D. Dança... ensino, sentidos e possibilidades na escola. Campinas, SP: Autores Associados, 2008.

BRASILEIRO, L. T. O conteúdo "dança" em aulas de educação física: temos o que ensinar? Revista Pensar a Prática, v. 6, p. 45-58, jul./jun., 2002-2003.

BRASILEIRO, L. T. O ensino da dança na Educação Física: formação e intervenção pedagógica em discussão. Motriz, Rio Claro, v. 14, n. 4, p. 519-528, out./dez., 2008.

BRASIL. Conselho Nacional de Educação. Resolução n. 3, de 16 de outubro de 1987. Brasília, DF, 1987

BRASIL. Ministério da Educação e Cultura. Lei de diretrizes e bases da educação nacional n.9.394, de 20 de dezembro de 1996. Diário Oficial da União, Brasília, DF, 20 dez. 1996. 
BRASIL. Secretaria de Educação Fundamental. Parâmetros curriculares nacionais: introdução aos parâmetros curriculares nacionais. Brasília, MEC, 1997.

BRASIL. Conselho Nacional de Educação/Conselho Pleno. Resolução n. 01, de 18 de fevereiro de 2002. Diário Oficial da União, Brasília, DF, 9 mar. 2002.

BRASIL. Conselho Nacional de Educação/Conselho Pleno. Resolução n. 02, de 19 de fevereiro de 2002. Diário Oficial da União, Brasília, DF, 4 mar. 2002.

BUOGO, E. D. B; LARA, L. M. Análise da dança como conteúdo estruturante da educação física nas diretrizes curriculares da educação básica do Paraná. Revista Brasileira de Ciências do Esporte, Florianópolis, v. 33, n. 4, p. 873-888, out./dez., 2011.

CERVO, A. L.; BERVIAN, P. A. Metodologia científica: para uso dos estudantes universitários. São Paulo: Mcgraw-hill do Brasil, 1996.

CORRÊA, J. F.; SANTOS, V. L. B. Dança na Educação Básica: apropriações de práticas contemporâneas no ensino de dança. Rev. Bras. Estud. Presença, Porto Alegre, v. 4, n. 3, p. 509-526, set./dez. 2014.

FARO, A. J. Pequena história da dança. Rio de Janeiro: Jorge Zahar,1986.

FIAMONCINI, L. A dança na educação: a busca de elementos na arte e na estética. Pensar a Prática. Goiânia n.6, p. 59-72, Jul./Jun. 2003.

GARIBA, C. M.; FRANZONI, A. Dança na escola: uma possibilidade em educação física. Movimento, Porto Alegre, v. 13, n. 2, p. 155-171, maio 2007.

GIL, A. C. Como elaborar projetos de pesquisa. 4. ed. São Paulo: Atlas, 2002.

GOMES JUNIOR, L. M.; LIMA, L. M. de; SOARES, A.; MACHADO, Z. Rítmica e dança nos currículos dos cursos de educação física. Revista Pensar a prática. Goiânia, v. 6, n. 3, p. 31-44, jul., 2002.

GUIMARÃES, G. Dança nos ciclos de escolarização: aproximações teóricas. Pensar a Prática. Goiânia n.6, p. 21-29, Jul./Jun. 2003.

GUZZO, M. S. L.; FEDERICI, C. A. G.; ROBLE, O. J,; TERRA, V. D. S. Dança é política para a cultura corporal. Pensar a Prática. Goiânia v. 18, n. 1, jan./mar. 2015.

LABAN, Rudolf. Domínio do Movimento. São Paulo: Summus, 1978.

LABAN, Rudolf. Dança Educativa Moderna. São Paulo: Ícone, 1990.

LARA, L. M. Corpo, dança e maracatu nação. Revista da Educação Física/UEM, Maringá, v. 18, supl., p. 163-166, 2007. 
MARQUES, I. A. Dançando na escola. Motriz, v. 3, n. 1, p. 20-28, jun., 1997.

MARQUES, I. A. Dançando na Escola. São Paulo: Cortez, 2003.

MARTINS, M. C. et alii. Arte na pedagogia. In: XXII CONFAEB Arte/Educação: corpos em trânsito. 26 ed., São Paulo. Anais... São Paulo: Instituto de Artes, Universidade Estadual Paulista, 29 de outubro a 02 de novembro de 2012, 19p.

MINISTÉRIO DA EDUCAÇÃO E CULTURA. Instituições de Educação Superior e Cursos Cadastrados. Disponível em: http://emec.mec.gov.br/. Acesso em: 11 de dezembro de 2013.

NEVES, J. L. Pesquisa qualitativa: características, usos e possibilidades. Caderno de Pesquisas em Administração, São Paulo, v.1, n.3, 2 sem. 1996.

OSSONA, Paulina. A Educação pela Dança. São Paulo Summus, 1988.

PARANÁ. Secretaria de Estado da Educação. Diretrizes Curriculares da Educação Básica. Educação Física. Curitiba: SEED, 2008.

PERES, A. T.; RIBEIRO, D. V. D. B.; MARTINS JUNIOR, J. A dança escolar de $1^{\mathrm{a}}$ a $4^{\mathrm{a}}$ série na visão dos professores de educação física das escolas estaduais de Maringá. Revista da Educação Física/UEM, Maringá, v. 12, n.1, p.19-26, 1. Sem., 2001.

SBORQUIA, S. P.; PÉREZ GALLARDO, J. S. As danças na mídia e as danças na escola. Revista Brasileira de Ciências do Esporte, Campinas, v. 23, n. 2, p. 105-118, jan., 2002.

SOUSA, N. C. P.; HUNGER, D. A. C. F.; CARAMASCHI, S. A dança na escola: um sério problema a ser resolvido. Motriz, Rio Claro, v.16 n.2 p.496-505, abr./jun., 2010.

SOUSA, N. C. P.; HUNGER, D. A. C. F.; CARAMASCHI, S. O ensino da dança na escola na ótica dos professores de Educação Física e de Arte. Rev Bras Educ Fís Esporte, São Paulo, v.28 n.3, p.505-20. jul-set 2014.

STRAZZACAPPA, M.; MORANDI, C. Entre a arte e a docência: a formação do artista de dança. Campinas, SP: Papirus, 2006.

STRAZZACAPPA, M. O swing do ensino de dança no Brasil: um balanço de quase duas décadas. In: Fórum Temático Dança na Educação Básica. Dança, Salvador, v. 3, n.1, p. 88104, jan./jul. 2014.

VANDRESSEN, D. S. O currículo disciplinar nas DCES/PR: uma proposta arraigada no projeto moderno e neoliberal. Revista Travessias. Cascavel, v 05, n.2, p.493 a 512, 2011. 


\title{
THE SUBJECTS RHYTHMIC AND DANCEABLE IN PHYSICAL EDUCATION COURSES IN LICENTIATE IN THE STATE OF PARANÁ
}

\begin{abstract}
The descriptive study aimed to analyze how they are organized the subjects rhythmic and danceable presents in physical educations course in the state of Paraná, with a view to identifying similarities and/or distances to the curriculum guidelines of basic education in the state. The data were composed by documents of 12 institutions that offer the physical education course in licentiate. For the handling of data was used the technique of content analysis and descriptive statistics. The results indicate that the courses offer subjects of rhythms and dance that differ between courses as the content and referential and that there are similarities between the program content, menus and objectives as recommended by the curricular guidelines.
\end{abstract}

Keywords: Dance. Physical Education. College education. Curriculum.

\section{LAS DISCIPLINAS DE RÍTMICA Y DANZA EN LICENCIATURA EN EDUCACIÓN FÍSICA DEL ESTADO DE PARANÁ}

\section{Resumen}

El estudio de carácter descriptivo tuvo como objetivo analizar la forma en que se organizan las disciplinas de rítmica y danza presente en los cursos de graduación en la educación física de Paraná, con miras a identificación de las similitudes y/o las distancias con las directrices curriculares de la educación básica en el estado. Los datos se componen de documentos de 12 instituciones que ofrecen licenciatura en educación física. Para el tratamiento de los datos se utilizó el análisis de contenido y la estadística descriptiva. Los resultados indican que los cursos ofrecen disciplinas rítmica y danza que difieren entre los cursos com respecto a los contenido y referenciais y que hay similitudes entre el contenido del programa, los menús y los objetivos, tal como recomiendan las directrices curriculares.

Palabras-clave: Danza. Educación física. Educación superior. Curriculum.

Recebido em: 11/12/2013

Revisado em: 08/06/2014

Aprovado em: 11/08/2015

Endereço para correspondência:

Deisy de Oliveira Silva

deisynha_oliveira@hotmail.com

Universidade Estadual de Maringá

Avenida Colombo, 5.790 - Campus Universitário

Centro

87020900 - Maringá, PR - Brasil 